\title{
Identification of the key excreted molecule by Lactobacillus fermentum related to host iron absorption
}

\author{
Ana González ${ }^{\text {a }}$, Natividad Gálvez ${ }^{\mathrm{a}}$, Jesús Martín ${ }^{\mathrm{b}}$, Fernando Reyes ${ }^{\mathrm{b}}$, Ignacio Pérez-Victoria ${ }^{\mathrm{b}, *}$, \\ Jose M. Dominguez-Vera ${ }^{a, *}$ \\ ${ }^{a}$ Departamento de Química Inorgánica and Instituto de Biotecnología, Universidad de Granada, 18071 Granada, Spain \\ ${ }^{\mathrm{b}}$ Fundación MEDINA, Avda. del Conocimiento 34, 18016 Armilla, Granada, Spain
}

\section{A R T I C L E I N F O}

\section{Article history:}

Received 8 September 2016

Received in revised form 6 January 2017

Accepted 1 February 2017

Available online 4 February 2017

\section{Keywords:}

Iron metabolism

Probiotic bacteria

Lactobacillus fermentum

Iron supplement

\begin{abstract}
A B S T R A C T
We have taken a vital step towards understanding why probiotic bacteria increase iron absorption in the gastrointestinal tract. We show here that Lactobacillus fermentum, one of the main probiotics of the microbiota, exhibits an extraordinary ferric-reducing activity. This activity is predominantly due to an excreted molecule: $p$-hydroxyphenyllactic acid (HPLA). Reduction of $\mathrm{Fe}(\mathrm{III})$ to $\mathrm{Fe}(\mathrm{II})$ is essential for iron absorption in the gastrointestinal tract. By reducing Fe(III), HPLA boosts Fe(II) absorption through the DMT1 channels of enterocytes. An in vitro experiment tested and confirmed this hypothesis. This discovery opens new avenues for the treatment of iron deficiency in humans, one of the most common and widespread nutritional disorders in the world.
\end{abstract}

(c) 2017 Elsevier Ltd. All rights reserved.

\section{Introduction}

Iron is an indispensable element for humans due to its involvement in essential biochemical processes, including energy production, biosynthesis, replication, and locomotion (Crichton, 2001; Silva \& Faustino, 2015). Iron deficiency is the most common and widespread nutritional disorder in the world. Besides affecting many children and women in developing countries, it is the only nutrient deficiency prevalent in industrialized countries. The human body receives iron from food. Though the daily requirement is $20-25 \mathrm{mg}$, no more than $2 \mathrm{mg}$ are really absorbed (Milto, Suhodolo, Prokopieva, \& Klimenteva, 2016). Adequate iron levels in the blood are partially maintained by recycling the iron released upon the degradation of iron-containing proteins, especially hemoglobin.

Heme-iron, present in hemoglobin and myoglobin, has high bioavailability (Huch \& Schaefer, 2006); however, the majority of iron in food $(>90 \%)$ is in non-heme forms, either as free iron or bound to low molecular-weight biomolecules (Crichton, Danielson, \& Geisser, 2008). Iron from food is mainly absorbed by the duodenum enterocytes (90\%). The stomach does not play a significant role in the assimilation of iron, as its absorption is no more than $2 \%$ of the total (Shayeghi et al., 2005).

\footnotetext{
* Corresponding authors.

E-mail address: josema@ugr.es (J.M. Dominguez-Vera).
}

Iron transfer through the enterocyte membrane occurs by the combined activities of two proteins: DMT1 and DcytB. The coupled work of DcytB/DTM1 is required for iron absorption since iron enters the small intestine lumen mainly as Fe(III), the result of $\mathrm{Fe}(\mathrm{II})$ oxidation by gastric juice components. Free $\mathrm{Fe}(\mathrm{III})$ is not able to enter into the enterocyte and must be reduced (Lane, Bae, Merlot, Sahni, \& Richardson, 2015; McKie, 2008). The ironregulated ferrireductase protein, DcytB, is highly expressed at duodenal enterocytes and reduces $\mathrm{Fe}(\mathrm{III})$ to $\mathrm{Fe}(\mathrm{II})$. Upon reduction, $\mathrm{Fe}(\mathrm{II})$ is transferred across the apical membrane of enterocytes by divalent metal transporters, mainly DMT1. Once inside the enterocytes, Fe(II) can be used for synthesis of iron-containing proteins, transported to plasma by the membrane protein ferroportin, or stored inside ferritin for later use when needed by cells (Lane et al., 2015; McKie, 2008).

Interestingly, the bioavailability of iron is influenced by a series of chemical species in the gastrointestinal tract. Whereas oxalates, phytates, phenolates and phosphates suppress iron absorption, ascorbic and citric acids, increase it (Conrad \& Umbreit, 2002). For this reason commercial iron supplements are usually accompanied by ascorbic or citric acid. Strategies to increase the intake of iron-rich foods, as well as dietary factors that enhance iron absorption, are therefore extremely important for human health.

Probiotic bacteria constitute an important part of natural microbiota. Bacteria produce many different metabolic substances that can act as antioxidants, bioflocculants or even immune 
activators (Lin et al., 2014; Peccia \& Kwan, 2016; Sommer \& Backhed, 2013). They survive the harsh stomach conditions and nest in different areas of intestines. Though the European Food Safety Authority (EFSA) has recently concluded that there is insufficient evidence to claim that a probiotic can help boost iron absorption (EFSA, 2016), other studies have shown that the probiotic bacteria of the human gut microbiota facilitate iron absorption (Bering, Suchdev, \& Sjoltov, 2006; Hoppe, Onning, Berggren, \& Hulthen, 2015; Perez-Conesa, Lopez, \& Ros, 2007). For example, it has been observed that the amount of probiotic bacteria in gut flora is significantly lower in anemic patients than in healthy people.

The mechanisms of this influence are not entirely understood. As of yet no compound excreted by bacteria has been shown to be related to iron absorption. Some have proposed that bacterial fermentation in intestines decreases the $\mathrm{pH}$ due to the production of lactic acid, which can increase iron solubility, leading to higher iron absorption (Hoppe et al., 2015). No published study has evaluated the effect of the ferric-reducing activity of probiotic bacteria on iron absorption. We show that Lactobacillus fermentum, one of the main components of the microbiota, exhibits considerable extracellular ferric-reducing activity. We have isolated and identified the excreted molecule that produces the ferricreducing activity of Lactobacillus fermentum: p-hydroxyphenyllactic acid (HPLA). This molecule efficiently reduces $\mathrm{Fe}(\mathrm{III})$ to $\mathrm{Fe}(\mathrm{II})$ at acidic $\mathrm{pH}$.

From the results described here, we propose that the increase of iron absorption in humans, due to the presence of probiotic bacteria in gut flora, could be related, not only to the decrease of $\mathrm{pH}$ caused by these lactic acid bacteria (Hoppe et al., 2015), but also to the ferric-reducing activity of the excreted HPLA. We have performed an in vitro experiment on iron uptake by enterocytes to confirm that HPLA promotes iron absorption. These results shed light on the reason why probiotic bacteria increase iron absorption in humans and can lead to more efficient strategies to increase iron absorption in humans.

\section{Materials and methods}

\subsection{Lactobacillus fermentum culture}

L. fermentum CECT5716 was grown in anaerobic conditions in a synthetic medium at $37{ }^{\circ} \mathrm{C}$ with orbital agitation for $24 \mathrm{~h}$ at an initial concentration of $1 \mathrm{mg}$ of bacteria per $\mathrm{ml}$ of medium. The synthetic medium consisted of $\left(\mathrm{g} \mathrm{l}^{-1}\right) \mathrm{Na}_{2} \mathrm{HPO}_{4}-5.0, \mathrm{KH}_{2} \mathrm{PO}_{4}-6.0$, trisammonium citrate -2.0 , sucrose $-50.0, \mathrm{MgSO}_{4}-1.0$ and trace elements solution $-10 \mathrm{ml}$ (consisting of $\left(\mathrm{g} \mathrm{l}^{-1}\right)$ : $\mathrm{MnSO}_{4}-2.0, \mathrm{CoCl}_{2}$ $-1.0, \mathrm{ZnCl}_{2}-1.0$ dissolved in $0.1 \mathrm{~N} \mathrm{HCl}$ solution). The medium with an initial pH 6.7 was sterilized at $121^{\circ} \mathrm{C}$. The final L. fermentum cell concentration was $3.3 \times 10^{8} \mathrm{CFU} \mathrm{ml}^{-1}$.

\subsection{Ferric-reducing activity of L. fermentum}

$1 \mathrm{ml}$ of bacterial culture was mixed with $3.6 \mu \mathrm{l}$ of a $10 \mathrm{mM} \mathrm{Fe}$ $\left(\mathrm{NO}_{3}\right)_{3} \cdot 9 \mathrm{H}_{2} \mathrm{O}$ water solution and $7 \mu \mathrm{l}$ of a $70 \mathrm{mM}$ 3-(2-pyridiyl)-5, 6-diphenyl-1,2,4-triazine- $p, p^{\prime}$-disulfonic acid monosodium salt hydrate (ferrozine, fz) water solution and the resulting mixture was incubated for 6 and $24 \mathrm{~h}$ and then centrifuged. The ferricreducing capacity of $L$. fermentum was measured by UV-vis spectroscopy through the apparition of a band centred at $562 \mathrm{~nm}$ due to the formation of the complex $\left[\mathrm{Fe}^{\mathrm{II}}(\mathrm{fz})_{3}\right]\left(\varepsilon^{562}=27,900 \mathrm{M}^{-1}\right)$. A control of the ferric-reducing activity of the culture media, without bacteria, showed no UV-vis band at $562 \mathrm{~nm}$. Similar ferricreducing activity was exhibited by the corresponding supernatant solution $(1 \mathrm{ml})$ from the bacterial culture.

\subsection{Isolation of excreted bacterial compound/s with ferric-reducing activity}

Bacteria were removed by centrifugation at $3000 \mathrm{~g}$ for $10 \mathrm{~min}$ and then the supernatant was filtered, using EMD Millipore Steritop $^{\mathrm{TM}}$ Sterile Vacuum Bottle-Top Filters. 21 of the filtered supernatant solution were subjected to solid-phase extraction on a column packed with SP-207ss brominated polystyrenic resin ( $65 \mathrm{~g}$ to render a column bed of $3.5 \mathrm{~cm}$ diameter and $11 \mathrm{~cm}$ height) previously equilibrated with water. The column was washed with water ( $1 \mathrm{l}$ ) and afterwards eluted with $200 \mathrm{ml}$ of methanol. The solvent was evaporated under a nitrogen stream and the resulting extract dissolved in $500 \mu \mathrm{l}$ of DMSO and further purified by reversed phase semi-preparative HPLC (Agilent Zorbax SB-C8, $9.4 \times 250 \mathrm{~mm}, 7 \mu \mathrm{m} ; 3.6 \mathrm{ml} / \mathrm{min}$, UV detection at 210 and $280 \mathrm{~nm}$ ) with a linear gradient of water-CH3CN (5\%-50\%) over $40 \mathrm{~min}$ to yield 80 fractions of $1.8 \mathrm{ml}$. The ferric-reducing activity of each fraction was tested, using a 96-well microtitre plate containing $2 \mu \mathrm{l}$ of each fraction diluted with $198 \mu \mathrm{l}$ of water. $1.08 \mu \mathrm{l}$ of a $10 \mathrm{mM} \mathrm{Fe}\left(\mathrm{NO}_{3}\right)_{3}$ stock solution and $2.1 \mu \mathrm{l}$ of a $70 \mathrm{mM}$ fz stock solution were added to each well. The presence of the complex $\left[\mathrm{Fe}^{\mathrm{II}}(\mathrm{fz})_{3}\right]$, determined by measuring the absorbance at $570 \mathrm{~nm}$, using a microplate reader (Envision 2104 multilabel reader. Perkin Elmer), was detected only in fractions 8-11. These fractions were pooled, evaporated and then dissolved in $1 \mathrm{ml}$ of distilled water. The resulting water solution was further purified by reversed phase semi-preparative HPLC (Waters Atlantis C18, $9.4 \times 250 \mathrm{~mm}, 7 \mu \mathrm{m} ; 3.6 \mathrm{ml} / \mathrm{min}$, UV detection at 210 and $280 \mathrm{~nm}$ ) with a linear gradient of water- $\mathrm{CH}_{3} \mathrm{CN}(0-25 \%)$ over $40 \mathrm{~min}$ to yield 80 fractions of $1.8 \mathrm{ml}$. The ferric-reducing activity of these fractions was tested as before. Only fractions 28 and 29 exhibited ferric-reducing activity. These fractions were pooled, evaporated and analyzed by LC-ESI-TOFMS and NMR spectroscopy.

\subsection{Structure elucidation of the excreted bacterial compound with ferric-reducing activity}

For NMR analysis, the sample (pooled dry fractions or the HPLA standard) was dissolved in deuterated methanol, $\mathrm{CD}_{3} \mathrm{OD}$. NMR spectra, including ${ }^{1} \mathrm{H}, \mathrm{COSY}, \mathrm{HSQC}$ and $\mathrm{HMBC}$, were recorded on a Bruker Avance III spectrometer (500 and $125 \mathrm{MHz}$ for $1 \mathrm{H}$ and 13C NMR, respectively) equipped with a $1.7 \mathrm{~mm}$ TCI MicroCryoProbeTM, using the signal of the residual deuterated solvent as internal reference $\left(\delta_{\mathrm{H}} 3.31\right.$ and $\left.\delta_{\mathrm{C}} 49.0 \mathrm{ppm}\right)$. LC-DAD-ESI-HRMS analysis of an aliquot of the final pooled fractions was performed on an Agilent 1200 rapid resolution HPLC system hyphenated with a Bruker maXis QTOF mass spectrometer, using a Zorbax SB-C8 column $(2.1 \times 30 \mathrm{~mm}, 5 \mu \mathrm{m})$, maintained at $40^{\circ} \mathrm{C}$ and with a flow rate of $300 \mu \mathrm{min}^{-1}$. Solvent A consisted of $10 \%$ acetronitrile and $90 \%$ water with $1.3 \mathrm{mM}$ trifluoroacetic acid and ammonium formate, and solvent B was $90 \%$ acetronitrile and $10 \%$ water with $1.3 \mathrm{mM}$ trifluoroacetic acid and ammonium formate. The gradient started at $10 \%$ B and went to $100 \%$ B in 6 min, kept at $100 \%$ B for 2 min and returned to $10 \%$ B for 2 min to initialize the system. Full diode array UV scans from 100 to $900 \mathrm{~nm}$ were collected in $4 \mathrm{~nm}$ steps at $0.25 \mathrm{~s} / \mathrm{scan}$. The mass spectrometer was operated in positive ESI mode. The instrumental parameters were: $4 \mathrm{kV}$ capillary voltage, drying gas flow of $111 \mathrm{~min}^{-1}$ at $200^{\circ} \mathrm{C}$, nebulizer pressure at 2.8 bars. TFA-Na cluster ions were used for mass calibration of the instrument prior to sample injection. Pre-run calibration was by infusion with the same TFA-Na calibrant. The structure of the target compound was established, using the NMR data. Its molecular formula was corroborated by the HRMS results. Further confirmation on the identity was obtained by direct comparison with the ${ }^{1} \mathrm{H}$ and HSQC NMR spectra of an HPLA standard prepared in $\mathrm{CD}_{3} \mathrm{OD}$. The corresponding test of ferric-reducing activity of the HPLA 
standard unequivocally determined this molecule as the target excreted compound responsible for such reducing power displayed by the $L$. fermentum culture.

\subsection{Ferric-reducing activity of HPLA vs $\mathrm{pH}$}

Racemic HPLA was acquired from Sigma-Aldrich. Solutions of HPLA $(144 \mu \mathrm{M})$ were prepared in different buffers with $\mathrm{pH}$ ranging from 3.0 to 7.4 and mixed with solutions of $10 \mathrm{mM} \mathrm{Fe}\left(\mathrm{NO}_{3}\right)_{3} \cdot 9 \mathrm{H}_{2} \mathrm{O}$ and $70 \mathrm{mM}$ of fz. Ferric-reducing activity of HPLA at these different $\mathrm{pH}$ values was measured by UV-vis spectroscopy through the appearance of a band centred at $562 \mathrm{~nm}$, due the formation of the complex $\left[\mathrm{Fe}^{\mathrm{II}}(\mathrm{fz})_{3}\right]\left(\varepsilon^{562}=27,900 \mathrm{M}^{-1}\right)$. The results showed that HPLA exhibits high ferric-reducing activity only at low $\mathrm{pH}$.

\subsection{Ferric-reducing activity of L. fermentum after HPLA addition}

The ferric-reducing capacity of $L$. fermentum was measured, as indicated above, after incubation for 6 and $24 \mathrm{~h}$. HPLA $(3.6 \mu \mathrm{M})$ was added to the supernatant obtained after centrifugation of the $6 \mathrm{~h}$ culture and the ferric-reducing activity of the resulting mixture was measured. The ferric-reducing activity of HPLA $(3.6 \mu \mathrm{M})$ in the medium grown was used as control.

\subsection{Ferric-reducing activity of HPLA versus lactic acid (LA),} $p$-methylphenol $(p-m P h)$ and the mixture $p$-methylphenol and lactic acid $(L A+p-m P h)$

Two different experimental conditions were assayed, excess and deficiency of $\mathrm{Fe}(\mathrm{III})$ with respect to the reducing molecules. The ferric-reducing activity was referred to the initial concentrations of $\mathrm{Fe}(\mathrm{III})$ or the chemical reductant, respectively.

A $50 \mathrm{mM}$ stock solution of HPLA was prepared by dissolving $9.1 \mathrm{mg}$ in $1 \mathrm{ml}$ of Mili-Q water. Solutions of LA and $p-\mathrm{mPh}$ at the same $50 \mathrm{mM}$ concentration were prepared, as well as a mixture solution of both $(\mathrm{LA}+p-\mathrm{mPh})$ containing $50 \mathrm{mM}$ of each reducing molecule. Lactic acid and $p$-methylphenol were also purchased from Sigma-Aldrich.

$110 \mu \mathrm{l}$ of each stock solution were added to $879 \mu \mathrm{l}$ of Mili-Q water containing $3.6 \mu \mathrm{l}$ of a $10 \mathrm{mM}$ solution of $\mathrm{Fe}\left(\mathrm{NO}_{3}\right)_{3} \cdot 9 \mathrm{H}_{2} \mathrm{O}$ and $7 \mu \mathrm{l}$ of a ferrozine solution $(70 \mathrm{mM})$. The $p$-methylphenol and lactic acid mixture was preparing by adding $110 \mu \mathrm{l}$ of the $p$-methylphenol stock solution and $110 \mu \mathrm{l}$ of the lactic acid stock solution to $769 \mu \mathrm{l}$ of Mili-Q water containing $3.6 \mu \mathrm{l}$ of a $10 \mathrm{mM}$ $\mathrm{Fe}\left(\mathrm{NO}_{3}\right)_{3} \cdot 9 \mathrm{H}_{2} \mathrm{O}$ solution and $7 \mathrm{l}$ of a $70 \mathrm{mM}$ fz solution. The final concentrations of the reducing molecules and $\mathrm{Fe}(\mathrm{III})$ were $5.5 \mathrm{mM}$ and $36 \mu \mathrm{M}$. The ferric-reducing activity of each sample was determined at $0,2,4$ and $24 \mathrm{~h}$ by monitoring the UV-vis band at $562 \mathrm{~nm}$ of the complex $\left[\left[\mathrm{Fe}^{\mathrm{II}}(\mathrm{fz})_{3}\right]\right.$. In a second experiment a $25 \mu \mathrm{M}$ concentration of each reducing molecule was used.

\subsection{In vitro experiment on iron internalization in enterocyte cells}

IEC6 epithelial rat small intestine cells were provided by the Scientific Instrumentation Centre (University of Granada, Spain). Cell line was grown adherently and maintained in DMEM $+2 \mathrm{mM}$ glutamine $+0.1 \mathrm{IU} / \mathrm{ml}$ of insulin $+5 \%$ of foetal bovine serum (FBS) at $37^{\circ} \mathrm{C}$ in $5 \% \mathrm{CO}_{2}$. All experiments were performed in 12 -well plates. Cells were seeded onto the plates at a density of $5 \times 10^{4}$ cells per well and incubated for $48 \mathrm{~h}$ prior to the experiments.

The wells were filled up to a final volume of $1 \mathrm{ml}$ with a water solution of $\mathrm{Fe}\left(\mathrm{NO}_{3}\right)_{3} \cdot 9 \mathrm{H}_{2} \mathrm{O}(360 \mu \mathrm{M})$, the grown medium and HPLA, at two different concentrations, 360 and $36 \mu \mathrm{M}$. Two more wells with a blank sample containing only cells were also prepared. Plates were incubated at $37^{\circ} \mathrm{C}$ for 0.5 or $5 \mathrm{~h}$. Samples were filtered, using a $0.2 \mu \mathrm{m}$ Minisart RC filter and the total iron concentration ( $\mathrm{Fe}(\mathrm{II})$ and $\mathrm{Fe}(\mathrm{III})$ ) measured by ICP-OES.

\subsection{Statistical analysis}

The ferric-reducing activity of HPLA versus LA, $p$ - $\mathrm{mPh}$ and the mixture $\mathrm{LA}+p-\mathrm{mPh}$ and the in vitro experiment on iron internalization in enterocyte cells were conducted in triplicates. Descriptive error bars represent the standard deviation (SD) of the triplicates and it was calculated using the $n-1$ method.

\section{Results and discussion}

\subsection{Lactobacillus fermentum shows a high ferric-reducing activity}

The ability to reduce $\mathrm{Fe}(\mathrm{III})$ to $\mathrm{Fe}(\mathrm{II})$ is usually related to the antioxidant properties of a chemical species. In the context of iron metabolism, this redox reaction is essential for iron absorption since non-heme iron is usually in the form of Fe(III), which cannot be absorbed by enterocytes until it has been reduced to $\mathrm{Fe}(\mathrm{II})$.

The ferric-reducing activity of $L$. fermentum was measured through its incubation with $\mathrm{Fe}(\mathrm{III})$ and ferrozine by monitoring the formation of the $\mathrm{Fe}(\mathrm{II})$ complex with the chelator, $\left[\mathrm{Fe}^{\mathrm{II}}(\mathrm{fz})_{3}\right]$, through the appearance and increase of its characteristic UV-vis band at $562 \mathrm{~nm}$. The supernatant liquid isolated after centrifugation of the bacteria exhibits activity similar to that of the bacterial broth after 6 and $24 \mathrm{~h}$ (Fig. 1). This evidence indicates that the ferric-reducing ability of $L$. fermentum is due to the molecule(s) excreted by the bacteria, However, the patterns of ferric-reducing activity of the supernatant and the bacterial culture differ. Whereas the former is able to reduce a specific amount of $\mathrm{Fe}(\mathrm{III})$ and then is rendered inactive, the latter exhibits prolonged activity. The bacterial culture can reduce additional amounts of $\mathrm{Fe}(\mathrm{III})$ after reducing the same amount of $\mathrm{Fe}(\mathrm{III})$ as reduced by the supernatant. This could be explained if the bacterium continuously excreted or regenerated the molecule responsible for its ferric-reducing activity.

The characterization of excreted active molecules by living organisms is of great interest in the biomedical field. In fact, some of these molecules are in the pharmaceutical market for different medical purposes. We addressed the challenge of isolating and characterizing the molecule responsible for the ferric-reducing activity of $L$. fermentum because no such study has been thus far done.

An assay-guided fractionation approach was implemented. First, an extract of the culture supernatant was prepared. A brominated polystyrenic resin (SP207ss), with the capacity to retain both

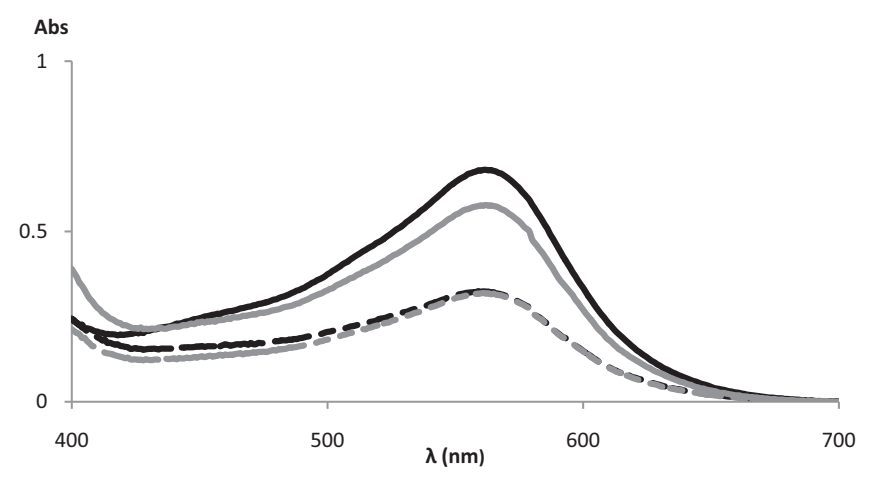

Fig. 1. Ferric-reducing activity of L. Fermentum (black line) and the supernatant liquid (grey line) after 6 (dashed lines) and $24 \mathrm{~h}$ (solid lines). Development of the UV-vis band centered at $562 \mathrm{~nm}$ due to $\left[\mathrm{Fe}^{\mathrm{II}}(\mathrm{fz})_{3}\right]$ informs of the ferric-reducing activity. 
polar and non-polar compounds, was used for the solid-phase. After confirming the ferric-reducing activity of the extract obtained by elution from the resin with methanol, the extract was subjected to semipreparative HPLC fractionation. After passing through a C8 reversed-phase column, the fractions with the reducing ability were pooled and further fractionated with a C18 column. The two fractions showing ferric-reducing activity were pooled and analyzed by NMR and LC-DAD-ESI-TOFMS. The ${ }^{1} \mathrm{H}$ NMR spectrum (Fig. 2) revealed a mixture of a few compounds. The signals of a para-hydroxyphenyl group, corresponding to one of the major components, could easily be identified. Additional 2D NMR experiments, including COSY, HSQC and HMBC (Supporting information S1-S8), were employed to elucidate the connectivity of the compound containing this structural moiety, which turned out to correspond to $p$-hydroxyphenyllactic acid (HPLA, Chart 1).

The molecular formula of HPLA, $\mathrm{C}_{9} \mathrm{H}_{10} \mathrm{O}_{4}$, was a major component detected in the corresponding LC-HRMS analysis (Supporting information S9).

Further confirmation of the identity of the compound was obtained by direct comparison of the NMR spectra of the final pooled active fractions with the spectrum of a commercial HPLA standard (Fig. 2). When the standard was evaluated for its ferricreducing activity, it showed the same reducing power. Thus, HPLA is the compound excreted by $L$. fermentum, responsible for the bacterial ferric-reducing activity.

Interestingly, HPLA has already been identified as an antioxidant compound, in a radical-scavenging assay, produced by the sister species Lactobacillus plantarum (Suzuki et al., 2013). The production of HPLA by lactic acid bacteria (LAB) was first reported from $L$. plantarum 21B (Lavermicocca et al., 2000). This compound has shown antifungal activity and contributes to the biopreservative properties claimed for LAB (Crowley, Mahonya, \& Sinderen, 2013). HPLA has been isolated as its L-enantiomer in L. plantarum (Suzuki et al., 2013). The same chirality is expected for the HPLA produced by the $L$. fermentum strain employed in this work, assuming a common pathway for HPLA production among lactobacilli. The biosynthesis of HPLA in LAB likewise explains the apparent regeneration of the ferric-reducing activity observed for $L$. fermentum in reduction experiments with increasing amounts of $\mathrm{Fe}(\mathrm{III})$. In these bacteria, tyrosine is transformed by transamination into 4-hydroxyphenylpyruvate, which is further reduced to HPLA by a hydroxyacid dehydrogenase (Lavermicocca et al., 2000; Li, Jiang, \& Pan, 2007; Valerio, Lavermicocca, Pascale, \& Visconti, 2004).<smiles>O=C(O)C(O)Cc1ccc(O)cc1</smiles>

Chart 1. Chemical structure of $p$-hydroxyphenyllactic acid HPLA.

Transamination is the rate-limiting step in such biosynthesis. It has been demonstrated that HPLA production dramatically increases in fermentations of Lactobacillus sp. SK007 supplemented with 4-hydroxyphenylpyruvate (tyrosine as supplement renders just a moderate increase in production) (Mu, Yang, Jia, Zhang, \& Jiang, 2010). These results indicate that the bacterium is very efficient in reducing 4-hydroxyphenylpyruvate to HPLA. Such efficiency would help to recycle the HPLA consumed in the reduction of $\mathrm{Fe}(\mathrm{III})$. In this ferrireduction HPLA gets oxidized to 4-hydroxyphenylpyruvate which would get back to HPLA via the corresponding Lactobacillus hydroxyacid dehydrogenase, that way explaining the apparent regeneration of the ferric-reducing activity already mentioned.

Once HPLA was identified as the molecule responsible for the ferric-reducing activity of $L$. fermentum, a study of its ability to reduce $\mathrm{Fe}(\mathrm{III})$ to $\mathrm{Fe}(\mathrm{II})$ as a function of $\mathrm{pH}$ was carried out. As shown in Fig. 3, HPLA exhibits a ferric-reducing activity extremely dependent on $\mathrm{pH}$. At $\mathrm{pH}$ above 6 , HPLA hardly reduces $\mathrm{Fe}(\mathrm{III})$ to $\mathrm{Fe}(\mathrm{II})$ but, at $\mathrm{pH} 3.8$, this reduction is practically complete.

To further verify that HPLA is the principal factor in the ferricreducing activity of $L$. fermentum, we performed an experiment in which HPLA was directly added to a $6 \mathrm{~h}$ bacterial culture. The resulting ferric-reducing activity of the mixture was compared to that of the $24 \mathrm{~h}$ bacterial culture. As shown in Fig. 4, the addition of HPLA to the culture media leads to an increase in the ferricreducing activity (Fig. 4, green bar). The activity of this mixture is close to the sum of that of $L$. fermentum (Fig. 4, blue bar) and the HPLA control (Fig. 4, red bar). Likewise, the addition of HPLA to the $6 \mathrm{~h}$ culture medium gives rise to a ferric-reducing activity close to that of the $24 \mathrm{~h}$ culture medium, indicating that HPLA is continuously excreted during the bacterial growth from 6 to $24 \mathrm{~h}$ and that this molecule is responsible for the ferric-reducing activity of $L$. fermentum.

Interestingly, HPLA seems to be a specific reductant of Fe(III). It does not reduce other chemical species, such as $\mathrm{Au}(\mathrm{III})$ or the

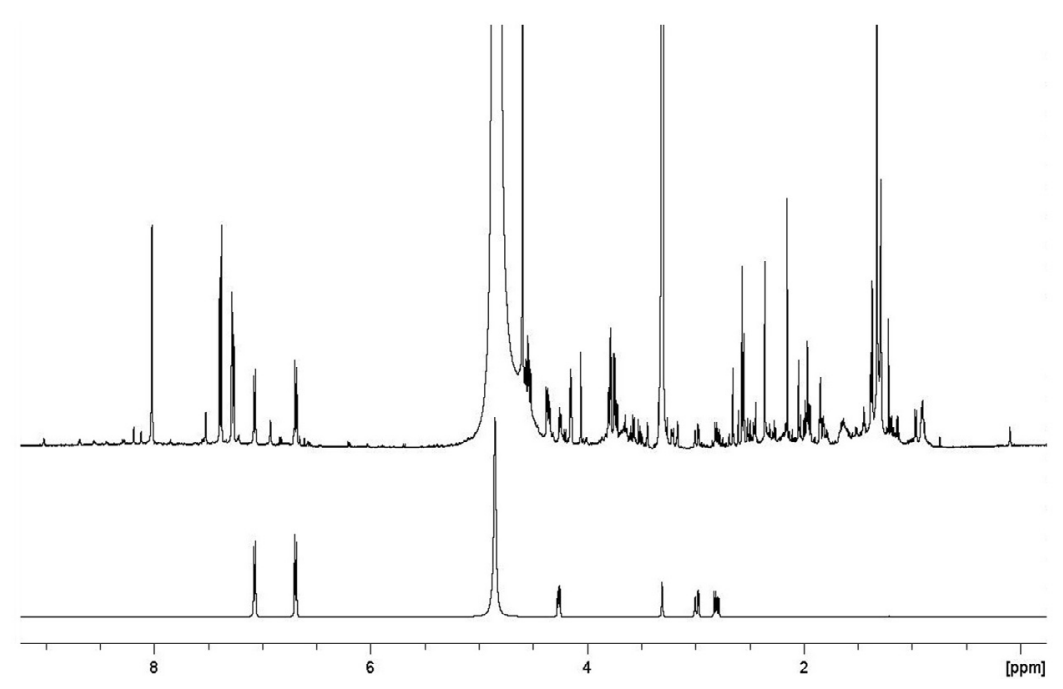

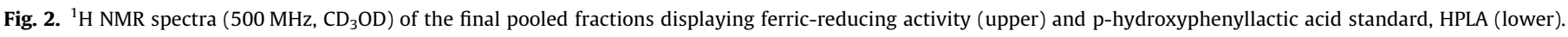




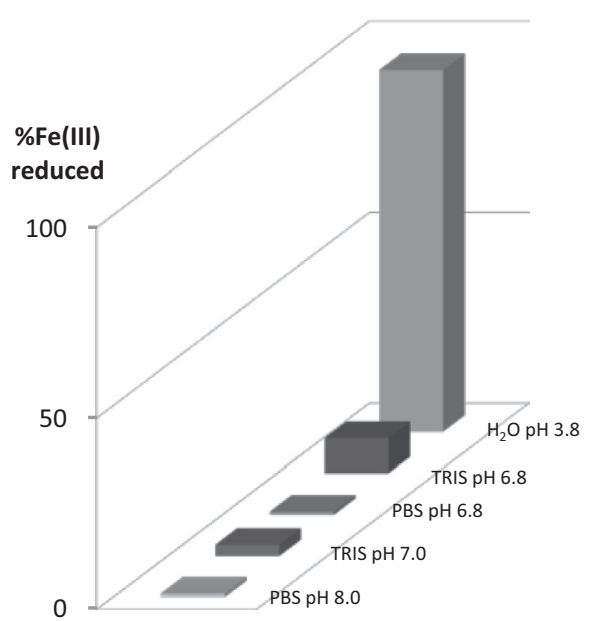

Fig. 3. Ferric-reducing activity of HPLA at different pHs and buffers. The \% of Fe(III) reduction was calculated as the ratio between concentrations of $\left[\mathrm{Fe}^{\mathrm{II}}(\mathrm{fz})_{3}\right]$ and the initial $\mathrm{Fe}(\mathrm{III})$.

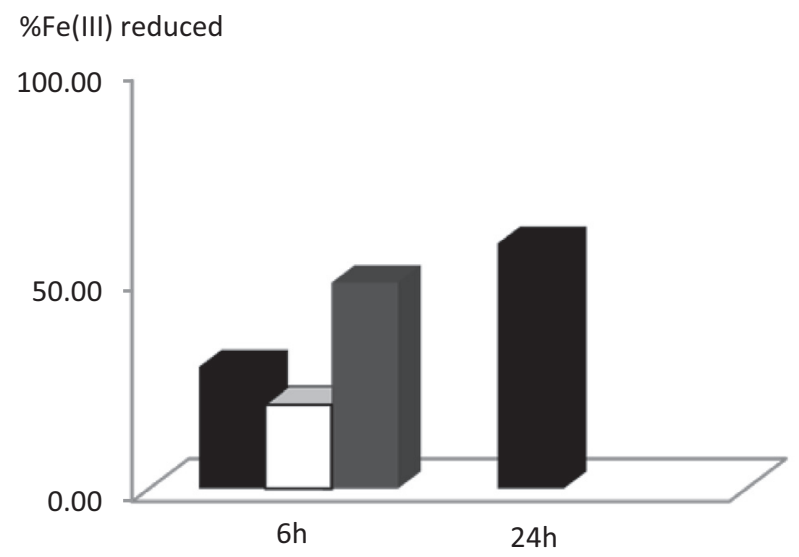

Fig. 4. Ferric-reducing activity, as a percentage of $\mathrm{Fe}(\mathrm{III})$ reduction, of a 6 and $24 \mathrm{~h}$ culture L. fermentum (black), the addition of HPLA $(3,6 \mu \mathrm{M})$ to the culture medium (white), and HPLA at the same concentration in the growth medium (grey).

polyoxometalate $\left[\mathrm{P}_{2} \mathrm{Mo}_{18}^{\mathrm{VI}} \mathrm{O}_{62}\right]^{6-}$, which are quite reduced in the presence of $L$. fermentum (Carmona, Martin, Galvez, \& DominguezVera, 2014; González, Gálvez, Clemente-León, \& Domínguez-Vera, 2015). This result indicates that the chemical reducing mechanism of $L$. fermentum does not solely contain HPLA but also other reducing molecules. Our work has reached a milestone in unravelling such a reducing mechanism after having being able to identify one of the molecules excreted by $L$. fermentum and label its functionality for future applications.

The characterization of HPLA as the main agent of the $\mathrm{pH}-$ dependent ferric-reducing activity of $L$. fermentum and its strong reducing ability dependence on $\mathrm{pH}$, provokes us to hypothesise that excreted HPLA could reduce Fe(III) under acid stomach conditions and facilitate $\mathrm{Fe}(\mathrm{II})$ absorption in the duodenum, as occurs for ascorbic and citric acids. Related studies report that low molecular weight fractions exhibiting ferric-reducing activity in human milk enhance iron absorption in newborns (Pullakhandama, Krishnapillai, Kasulab, Kilaria, \& Thippandea, 2008).

HPLA contains two chemical moieties with potential reducing $\mathrm{Fe}(\mathrm{III})$ activity: the terminal lactic acid and the phenol group. To get insight into the mechanism of the ferric-reducing activity of HPLA, we compared the HPLA ability to reduce Fe(III) at acidic $\mathrm{pH}$ with that of its pure chemical moieties, namely lactic acid (LA) and $p$-methylphenol $(p-\mathrm{mPh})$, and the mixture of both
$(\mathrm{LA}+p-\mathrm{mPh})$. Both an excess of reducing molecules with respect to $\mathrm{Fe}(\mathrm{III})$ and a slight excess of $\mathrm{Fe}(\mathrm{III})$ with respect to the active molecules were examined. The first was to understand the kinetics of $\mathrm{Fe}(\mathrm{III})$ reduction and the second was to evaluate the ferricreducing activity of the individual chemical moieties.

The most interesting result of these experiments is that HPLA reduces $\mathrm{Fe}(\mathrm{III})$ to the same extent as the mixture of lactic acid and $p-\mathrm{mPh}$, practically doubling the reducing capacity of separated LA and $p$-mPh (Fig. 5). Thus, both HPLA chemical moieties are effective for $\mathrm{Fe}(\mathrm{III})$ reduction and exhibit ferric-reducing activity. When the experiment was done in excess of $\mathrm{Fe}(\mathrm{III})$ towards the reducing molecules, the ferric-reducing activity vs. time revealed that HPLA seems to reduce Fe(III), first by the LA moiety and then by $p$-mPh (Fig. $5 \mathrm{~A})$. Fe(III) reduction versus time shows that the reduction by HPLA follows the same pattern as LA in the initial steps. The\%Fe(III) reduction was about $20 \%$ by HPLA and $15 \%$ by LA after $2 \mathrm{~h}$, whereas that of $p$-mPh was $90 \%$. This indicates that pure $p$-mPh has faster $\mathrm{Fe}(\mathrm{III})$ reduction mechanisms than LA and HPLA. However, over a prolonged period of time $(24 \mathrm{~h})$, the $\%$ $\mathrm{Fe}(\mathrm{III})$ reductions of HPLA, $p-\mathrm{mPh}$, and the mixture, $\mathrm{LA}-p-\mathrm{mPh}$, are similar and close to $100 \%$, whereas that of LA is about $80 \%$.

In the second experiment, $\mathrm{Fe}(\mathrm{III})$ was in excess with respect to the reducing molecules. The results clearly indicate that the capacity of HPLA to reduce Fe(III) is double than that of LA and of $p-\mathrm{mPh}$ and is close to the capacity of the mixture of both (Fig. 5B). Therefore, the combination of both chemical moieties (lactic acid and phenol) makes HPLA an extraordinary Fe(III) reducing molecule.

An in vitro experiment of iron uptake by enterocytes in the presence of HPLA was performed to test whether HPLA could be related to the effect on iron absorption by probiotic bacteria, (Fig. 6). HPLA was incubated at two concentrations ( 36 and $360 \mu \mathrm{M}$ ) with enterocytes (IEC-6 cells) in the presence of $\mathrm{Fe}(\mathrm{III})$. L. fermentum, and its supernatant liquid obtained after bacterial centrifugation, were also incubated with IEC-6 enterocytes and Fe(III). The concentration of total iron (Fe(II) and $\mathrm{Fe}(\mathrm{III})$ ) of the solutions was measured at two different times ( 30 and $300 \mathrm{~min}$ ), by ICP-OES, to evaluate the amount of iron internalized into the cells.

The first conclusion drawn from these data is that $L$. fermentum and its supernatant liquid significantly increased iron absorption by enterocytes. Values for Fe(III) absorption after incubation with enterocytes are very close to initial values, meaning that enterocytes hardly absorb Fe(III) (Fig. 6). In contrast, both enterocytes with $L$. fermentum and enterocytes with the supernatant (the excreted molecules) reduce iron concentrations to less than half those of the controls. Thus, the bacteria and excreted molecules facilitate enterocyte iron uptake. Moreover, enterocyte iron absorption by bacteria and by supernatant liquid obtained after centrifugation are similar, which substantiates that the effect of probiotic bacteria on iron absorption is due to the molecules excreted by these bacteria.

HPLA is less effective in assisting enterocytes with iron absorption than the bacterial broth or its supernatant liquid. However, higher HPLA concentrations $(360 \mu \mathrm{M})$ result in more absorption. Iron concentrations decrease from approximately $350 \mu \mathrm{M}$ (Fig. 6, columns 2) to 231 and $211 \mu \mathrm{M}$ after 30 and 300 min of incubation, respectively. While the higher concentration of HPLA $(360 \mu \mathrm{M})$ increases enterocyte iron uptake by about $40 \%$, the increase for the lower HPLA concentration $(36 \mu \mathrm{M})$ is only about $30 \%$.

Though HPLA clearly increases enterocyte iron absorption, the higher quantities of enterocyte iron absorption by L. fermentum and its supernatant liquid with respect to HPLA suggest that other molecules excreted by the probiotic bacteria must also be involved in this complex process. Lactic acid is a likely candidate, since $L$. fermentum is defined as a lactic bacterium that excretes this molecule while proliferating. 

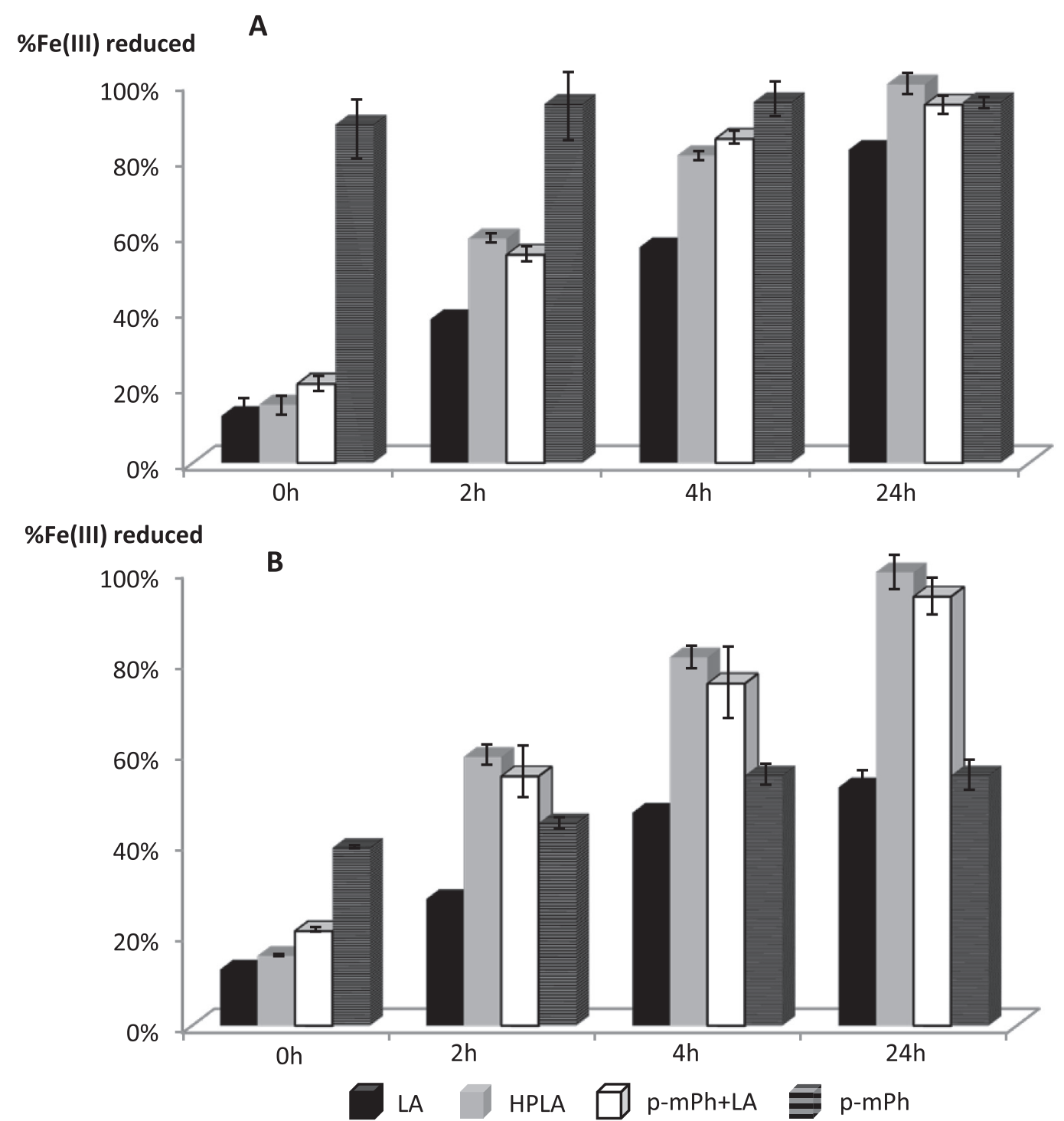

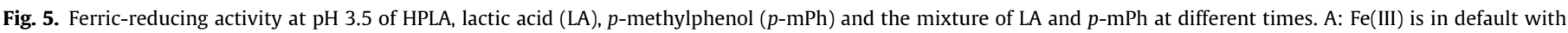

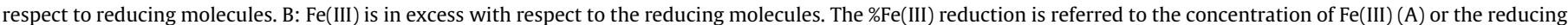
molecules (B). Error bars, \pm SD.

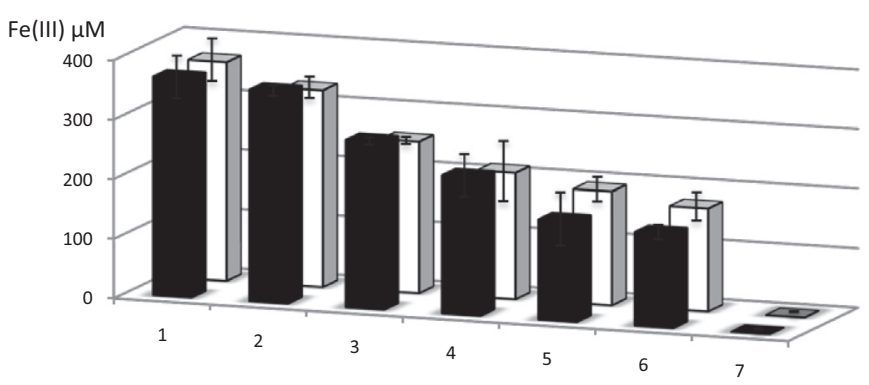

Fig. 6. Fe(III) $(367 \mu \mathrm{M})$ was incubated with enterocyte cells IEC-6 in the presence of HPLA at $36 \mu \mathrm{M}$ (columns 3), $360 \mu \mathrm{M}$ (columns 4), L. fermentum (columns 5) and the supernatant liquid obtained after centrifugation of $L$. fermentum (columns 6 ). Fe concentrations in the solutions were measured by ICP-OES after 30 (black) and 300 min (white). Columns 1 corresponds to the initial Fe(III) solutions; columns 2 corresponds to Fe(III) after incubation with IEC-6 (control) and columns 7 data to the plates only containing cells (control). Error bars, \pm SD.
Therefore, HPLA exhibits extraordinary ferric-reducing activity and increases enterocyte iron uptake. Taking into account enterocytes in the duodenum and the participation of the ferricreducing protein DcytB (Lane et al., 2015; McKie, 2008), our results point to a mechanism of iron absorption in which HPLA would act similarly to DcytB by facilitating $\mathrm{Fe}(\mathrm{III})$ reduction in the stomach and ultimately promoting Fe(II) uptake by DMT1 channels.

\section{Conclusions}

L. fermentum, one of the main probiotics of the microbiota, exhibits an extraordinary ferric-reducing activity. This activity is mainly due to one of the molecules excreted by this bacterium: p-hydroxyphenyllactic acid (HPLA). HPLA effectively reduces $\mathrm{Fe}(\mathrm{III})$ to $\mathrm{Fe}(\mathrm{II})$ and in the gastroinstestinal tract can mimic the functionality of the DcytB ferric-reducing protein by promoting iron uptake by enterocytes. We have demonstrated that the increase of iron absorption in the presence of probiotic bacteria is related to the ferric-reducing activity of excreted molecules. 
These results are a huge step towards solving the enigma of why probiotic bacteria increase iron absorption. This discovery opens new avenues for the treatment of human iron deficiency, one of the most common and widespread nutritional disorders in the world.

\section{Acknowledgements}

This work was funded by MINECO and FEDER (project CTQ2015-64538-R) and Biosearch S.A. (CARMENTA Project-FEDER INTERCONECTA). The HPLC and NMR equipment used in this work were acquired via grants for scientific and technological infrastructures from the MINECO [Grants Nos. PCT-010000-2010-4 (NMR) and INP-2011-0016-PCT-010000-ACT6 (HPLC)].

\section{Appendix A. Supplementary data}

Supplementary data associated with this article can be found, in the online version, at http://dx.doi.org/10.1016/j.foodchem.2017. 02.008 .

\section{References}

Bering, S., Suchdev, S., \& Sjoltov, L. (2006). A lactic acidfermented oat gruel increases non-haem iron absorption from a phytate-rich meal in healthy women of childbearing age. British Journal of Nutrition, 96(1), 80-85.

Carmona, F., Martin, M., Galvez, N., \& Dominguez-Vera, J. M. (2014). Bioinspired magneto-optical bacteria. Inorganic Chemistry, 53(16), 8565-8569.

Conrad, M., \& Umbreit, J. (2002). Pathways of iron absorption. Blood Cells, Molecules, and Diseases, 29(3), 336-355.

Crichton, R. (2001). Inorganic biochemistry of iron metabolism: From molecular mechanisms to clinical consequences. England: John Wiley \& Sons.

Crichton, R., Danielson, B., \& Geisser, P. (2008). Irontherapy with special emphasis on intravenous administration (4th ed.). London-Boston: International Medical Publishers.

Crowley, S., Mahonya, J., \& Sinderen, D. V. (2013). Current perspectives on antifungal lactic acid bacteria as natural bio-preservatives. Trends in Food Science E' Technology, 33(2), 93-109.

EFSA Panel on Dietetic Products and Allergies (NDA) (2016). Scientific opinion on dietary reference values for vitamin D. European Food Safety Authority (EFSA).

González, A., Gálvez, N., Clemente-León, M., \& Domínguez-Vera, J. M. (2015). Electrochromic polyoxometalate material as a sensor of bacterial activity. Chemical Communications, 51, 10119-10122.
Hoppe, M., Onning, G., Berggren, A., \& Hulthen, L. (2015). Probiotic strain Lactobacillus plantarum 299v increases iron absorption from an ironsupplemented fruit drink: A double-isotope cross-over single-blind study in women of reproductive age. British Journal of Nutrition, 114(8), 1195-1202.

Huch, R., \& Schaefer, R. (2006). Iron deficiency and iron deficiency anaemia. Pocket Atl. (pp. 1-70). New York: Thieme Medical Publishers.

Lane, D. J., Bae, D. H., Merlot, A. M., Sahni, S., \& Richardson, D. R. (2015). Duodena cytochrome b (DCYTB) in iron metabolism: An update on function and regulation. Nutrients, 7(4), 2274-2296.

Lavermicocca, P., Valerio, F., Evidente, A., Lazzaroni, S., Corsetti, A., \& Gobbetti, M (2000). Purification and characterization of novel antifungal compounds from the sourdough Lactobacillus plantarum strain 21B. Applied and Environmental Microbiology, 66(9), 4084-4090.

Li, X., Jiang, B., \& Pan, B. (2007). Biotransformation of phenylpyruvic acid to phenyllactic acid by growing and resting cells of a Lactobacillus sp. Biotechnology Letters, 29(4), 593-597.

Lin, C. S., Chang, C. J., Lu, C. C., Martel, J., Ojcius, D. M., Ko, Y. F., et al. (2014). Impact of the gut microbiota, prebiotics, and probiotics on human health and disease. Biomedical Journal, 37(5), 259-268.

McKie, A. T. (2008). The role of Dcytb in iron metabolism: an update. Biochemical Society Transactions, 36(6), 1239-1241.

Milto, I. V., Suhodolo, I. V., Prokopieva, V. D., \& Klimenteva, T. K. (2016). Molecular and cellular bases of iron metabolism in humans. Biochemistry, 81(6), 549-564.

Mu, W., Yang, Y., Jia, J., Zhang, T., \& Jiang, B. (2010). Production of 4hydroxyphenyllactic acid by Lactobacillus sp. SK007 fermentation. Journal of Bioscience and Bioengineering, 109(4), 369-371.

Peccia, J., \& Kwan, S. E. (2016). Buildings, beneficial microbes, and health. Trends in Microbiology, 24(8), 595-597.

Perez-Conesa, D., Lopez, G., \& Ros, G. (2007). Effect of probiotic, prebiotic and synbiotic follow-up infant formulas on iron bioavailability in rats. Food Science and Technology International, 13(1), 69-77.

Pullakhandama, R., Krishnapillai, M. N., Kasulab, S., Kilaria, S., \& Thippandea, T. G. (2008). Ferric reductase activity of low molecular weight human milk fraction is associated with enhanced iron solubility and uptake in Caco-2 cells. Biochemical and Biophysical Research Communications, 374, 369-372.

Shayeghi, M., Latunde-Dada, G. O., Oakhill, J. S., Laftah, A. H., Takeuchi, K., Halliday, N., et al. (2005). Identification of an intestinal heme transporter. Cell, 122(5), $789-801$.

Silva, B., \& Faustino, P. (2015). An overview of molecular basis of iron metabolism regulation and the associated pathologies. Biochimica et Biophysica Acta, 1852 (7), 1347-1359.

Sommer, F., \& Backhed, F. (2013). The gut microbiota-masters of host development and physiology. Nature Reviews Microbiology, 11(4), 227-238.

Suzuki, Y., Kosaka, M., Shindo, K., Kawasumi, T., Kimoto-Nira, H., \& Suzuki, C. (2013) Identification of antioxidants produced by Lactobacillus plantarum. Bioscience, Biotechnology, and Biochemistry, 77(6), 1299-1302.

Valerio, F. Lavermicocca, P. Pascale, M. \& Visconti, A (2004). Production of phenyllactic acid by lactic acid bacteria: An approach to the selection of strains contributing to food quality and preservation. FEMS Microbiology Letters, 233(2) 289-295. 